\title{
P3.336 SEROPREVALENCE OF HUMAN IMMUNODEFICIENCY VIRUS (HIV)INFECTION AMONGST TUBERCULOSIS(TB) PATIENTS ATTENDING TB/DOTS CENTRE IN NNEWI SOUTH EAST NIGERIA
}

doi:10.1136/sextrans-2013-051184.0789

C N Ogbuagu. Nnamdi Azikiwe University Teaching Hospital (NAUTH), Nnewi, Nigeria

Background The Nnamdi Azikiwe University Teaching Hospital (NAUTH) Nnewi is a centre for free laboratory and x-ray investigations, management of tuberculosis and HIV infection in the South Eastern Nigeria.

Method The authors conducted a retrospective study using the medical records of patients aimed at determining the prevalence of HIV infection in Tuberculosis (TB) patients attending Directly Observed Treatment Short-course (DOTS) services between April 2008 and December 2010. Pattern of TB/HIV co-infection rate over time was also analysed.

Result The study showed a high prevalence of HIV among TB patients $(29.9 \%)$. Smear Positive (SPT) was the most frequent $(60.6 \%)$ form of TB diagnosis. Extra Pulmonary Tuberculosis (EPT) and Smear Negative Tuberculosis (SNT) were frequently associated with HIV co-infection $(60.9 \%)$ and $(62.9 \%)$ respectively. HIV prevalence and TB was higher in females (15.6\%) than males $(14.1 \%)$ though not statistically significant.

Conclusion The co-infection rate was highest among individuals aged $27-34$ years $(10.9 \%)$ followed by $35-42$ years $(8.1 \%)$ and least among 60years and above $(0.6 \%)$. The increase in TB/HIV co-infection rate was monotonic over time with a strong trend among females aged $27-34$ years(25.7\%,21.6\% and 21.3\%) for 2008,2009 and 2010 respectively. 


\section{Retraction}

Ogbuagu CN. P3.336 Seroprevalence of Human Immunodeficiency Virus (HIV) Infection Amongst Tuberculosis (TB) Patients Attending TB/DOTS Centre in Nnewi South East Nigeria. Sex Transm Infect 2013;89:A254. This abstract has been retracted at the request of the author.

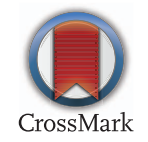

Sex Transm Infect 2014;90:407. doi:10.1136/sextrans-2013-051184.0789ret 